\title{
RELATIOSHIP BETWEEN FOAMINESS OF SALIVA AND ITS CHEMICAL COMPOSITIONS
}

\author{
BY \\ TAKESHI KIKUCHI* \\ I INTRODUCTION
}

Earlier, Mr. Sakamoto ${ }^{1)}$ of our department reported his findings in regard to the important hygienic significance of foaminess of human saliva and Mr. Akizuki ${ }^{2)}$ also of our department arrived at the conclusion that the foaming phenomenon of saliva affords an effective clue for judging the susceptibility of tooth to dental caries.

In an attempt to inquire into the nature of foaminess of saliva further, the author has conducted the following experiments so as to find out how the chemical composition of saliva affects its foaminess.

\section{Experimental Materials and Method}

A certain amount of resting mixed saliva and mixed saliva under the stimulation with pilocarpine was collected respectively from a healthy adult after an elapse of two hours from his meal in each case. For the collection of pilocarpine stimulated saliva, the subcutaneous injection of $1.0 \mathrm{mg}$ pilocarpine hydrochloride at the rate of $10 \mathrm{~kg}$ of the body weight was given and saliva (resting saliva) prior to 30 minutes of this injection and saliva after the injection at an interval of a quarter of an hour was collected into separate containers. The saliva which was collected after the first quarter of an hour was designated "Saliva of first quarter" and that of the second quarter of an hour was designated "Saliva of second quarter," saliva being collected as far as "Saliva of third quarter" and "Saliva of fourth quarter" in the like manner.

Immediately after the collection, saliva was subjected to the saking method under cumulative addition of $\mathrm{NaCl}$ solution in order to measure its total foam volume, which was later used as the standard of foaminess. At the same time with the above process, the chemical constituents of saliva were quantitatively measured as soon as possible.

Then the comparison was struck between the movement of foaminess and that of quantities of chemical constituents of saliva for the purpose of inferring the relationship between the two.

\section{Results}

It has been found that there exists much individual variation in the movement

* 菊池武: Dept. of Biochemistry, College of Dentistry, Nihon Univ. (Director: Prof. Atsushi OSHIKANE 
of foaminess, that is to say, the total foam volume curves. As is shown on Fig. 1, the total foam volume curves are classified into 8 types with the rates of their respective appearance.

Fig. 1. Curves and Rates of Their Appearances in Total Foam Volumes (Resting Saliva and Pilocarpine Stimulated Saliva)
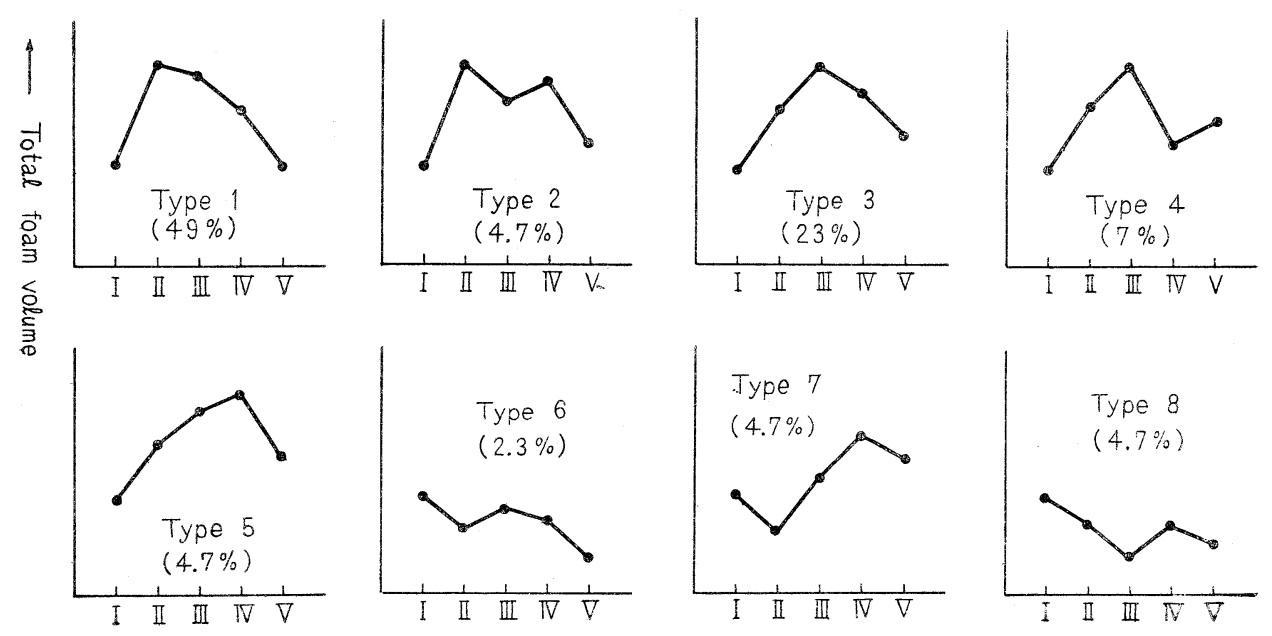

I Resting saliva II First quarter saliva III Second quarter saliva

IV Third quarter saliva $\mathrm{V}$ Fourth quarter saliva.

As the Type 1 predominates with $49 \%$, it has been taken up as the standard type and when the curves of chemical constituents run parallel to or opposite from this curve, it can be judged that a relationship between the two is very intimate.

The chemical constituents which have been found to run parallel to the Type 1 (the standard type) are $\mathrm{Cl}$ (by VanSlyke quantitative method of blood $\mathrm{Cl}$ ), total $\mathrm{N}$ (by micro-Kjeldahl), albumin- $\mathrm{N}$ (total $\mathrm{N}$ from which globulin- $\mathrm{N}$, mucin- $\mathrm{N}$ and $\mathrm{NH}_{3}-\mathrm{N}$ ), globulin- $\mathrm{N}$ ( $\mathrm{N}$ which is obtained in the sediments produced by saturation of magnesium sulfate that has been added to the supernatant fluid minus mucin) and amylase value (by Willstätter-Waldschmidt-Leitz-Hesse method). Refer to Fig. 2.

Of them, the type of amylase value curve and rate of its appearance quite resemble those of the total foam volume curves (Fig. 3).

It has been found, however, that even after the effect of amylase was destroyed by heating saliva at $100^{\circ} \mathrm{C}$ for five minutes, not much of a change was discerned in its foaminess. The chemical constituents which have been found to show the curves crossing diagonally the Type 1 (the standard type) are total C (extracted from the incinerated saliva by oxalate-potassium permanganate method), absolute Ca (by Kramer-Tisdall method in regard to the deproteinized saliva), total $\mathrm{P}$ (by Bell-Doisy method in regard to the deproteinized saliva) and mucin- $\mathrm{N}$ (measured by the micro-Kjeldahl method in regard to $\mathrm{N}$ precipitate which was produced by the addition of an equal amount of acetic acid to saliva). Refer to Fig. 4. 
Fig. 2. Chemical Constituents Running Parallel to Total Foam Volume Curves

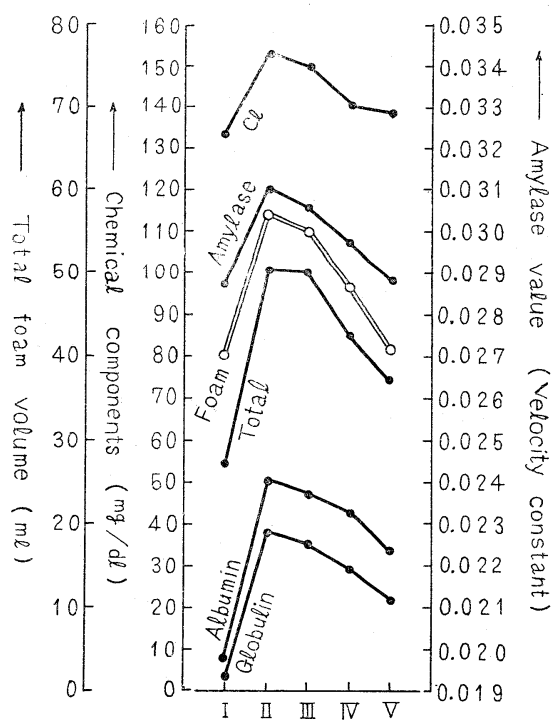

I Resting saliva II First quarter saliva

III Second quarter saliva IV Third quarter saliva

$\mathrm{V}$ Fourth quarter saliva

Fig. 3. Types and Rates of Appearance of Amylase Value Curves
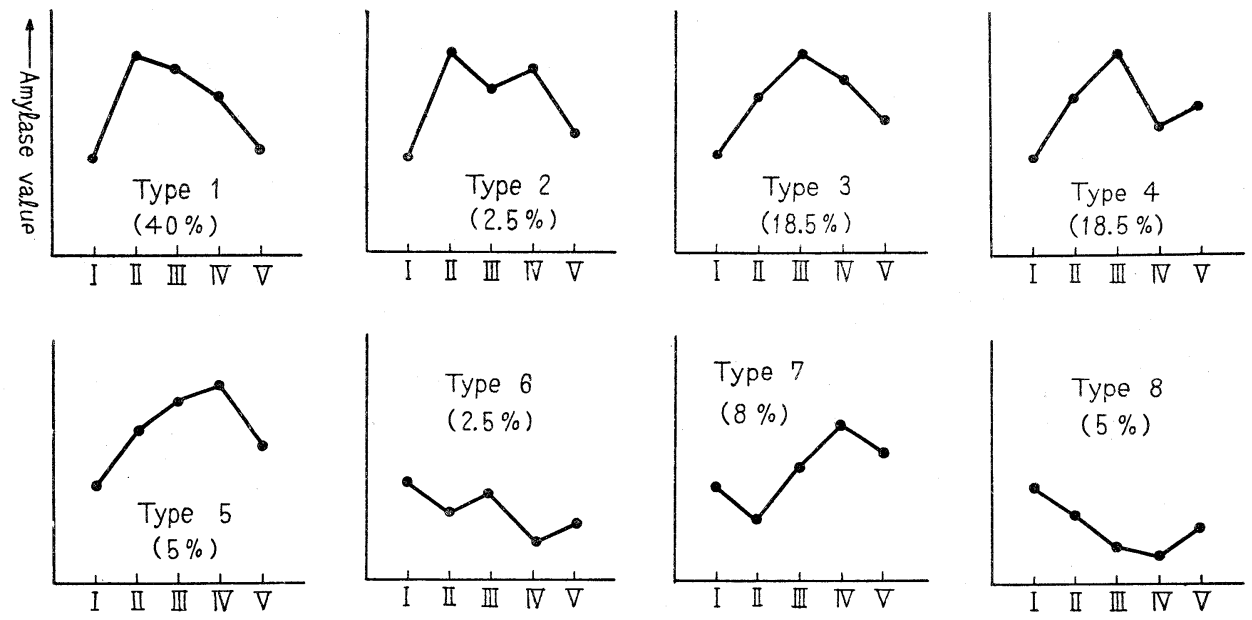

Legend: I Resting saliva II First quarter saliva III Second quarter saliva IV Third quarter saliva $\mathrm{V}$ Fourth quarter saliva

It is found that the foaminess of saliva is heightened much more than the original state, when mucin has been deprived of saliva by means of acetic acid. 
Fig. 4. Chemical Constituents with Curves Crossing Diagonally Total Foam Volume Curves

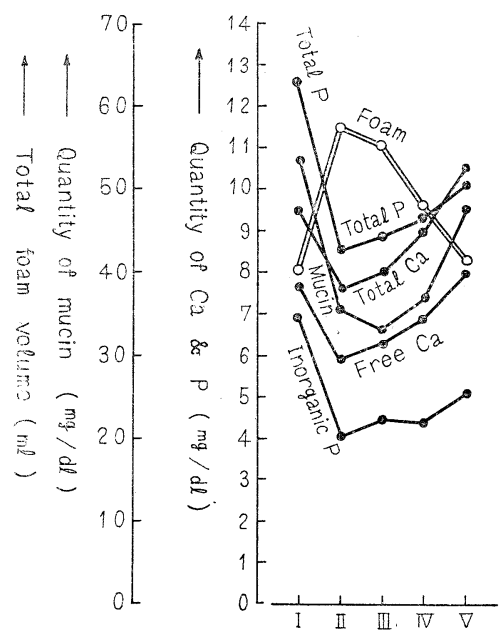

I Resting saliva II First quarter saliva

III Second quarter saliva IV Third quarter saliva

$\mathrm{V}$ Fourth quarter saliva

(In our experiment the degrees of dilution and $\mathrm{pH}$ of acetic acid were made the same as those of saliva.)

$\mathrm{Mg}$ (extracted by the phosphate method of Bell-Doisy), $\mathrm{CO}_{2}$ (by Warburg apparatus), $\mathrm{NH}_{3}$ (by Folin-McCallum method), $\mathrm{pH}$ and total reducing power (measured by the quantitative determination method of blood sugar, however, without the filtration of $\mathrm{Zn}(\mathrm{OH})_{2}$ precipitation), are the chemical constituents which have been found as having no direct bearing upon the foaminess of saliva. Within the physiological range of saliva $\mathrm{pH}$ (approximately from 6 to 8), there has been observed no relationship between the series of $\mathrm{pH}$ and that of saliva foaminess. However, when its $\mathrm{pH}$ was modified in the extreme degree by the addition of an acid or alkali, the foaminess of saliva was also changed proportionately, with many individual variations in its change thus making it impossible for a certain law to be enacted.

In another experiment, the part of saliva which failed to form foams when agitated was further separated and it was again agitated in order to produce foams. As the result of this kind of cumulative formation test of foam, it has been found that the foaminess gradually decreases with the $\mathrm{N}$ quantity becoming lower in parallel degrees.

\section{Conclusions}

The foaminess and chemical compositions of resting saliva differ from those of saliva produced under stimulation of pilocarpine and of the chemical compositions, $\mathrm{Cl}$, protein and amylase (not the enzymic action of amylase itself) are conclusively 
established as having intimate bearing upon the saliva foaminess and among those which interfere with this foaming function of saliva are included $\mathrm{Ca}, \mathrm{P}$ and mucin.

In summary, it can be considered that the chemical factors which control and influence the foaminess of saliva are quite multiple and complex and respective forms of the saliva foaminess are attributed to the mutual function and influence of those various chemical factors on one another.

\section{REFERENCES}

1) K. Sakamoto: Hygienic Study on Foaming Phenomenon of Human Saliva, Dent. J. Nihon Univ., Vol. 1 (June 1958).

2) T. AKIzUkI : Studies on Relations between Saliva and Its Susceptibility to Dental Caries, Dent. J. Nihon Univ., Vol. 1 (June 1958). 